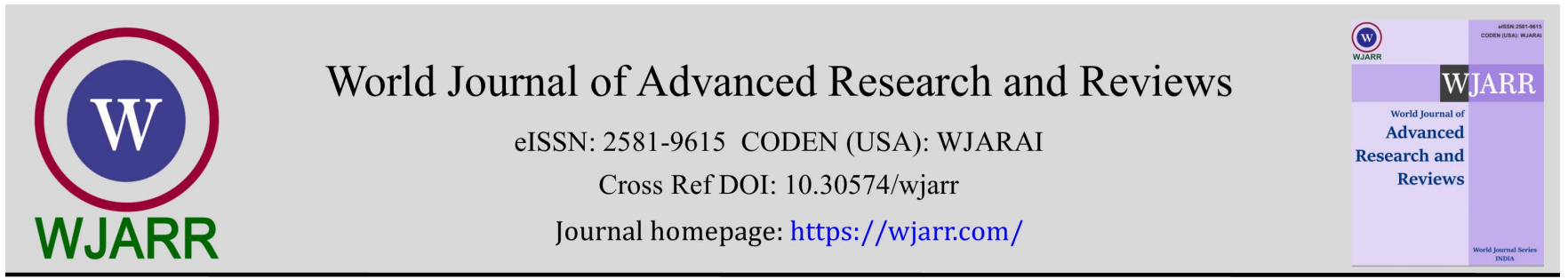

(RESEARCH ARTICLE)

\title{
Effect of shelling speed, moisture content and number of beaters on the cleaning and recovery efficiency of a mechanized centrifugal Melon shelling machine
}

\author{
Oluwabukola Belinda Aturu 1, Joshua Olanrewaju Olaoye 1, Agidi Gbabo 2, Ibrahim Mohammed Gana 3*, Ndudi \\ Efomah Andrew ${ }^{4}$ and Jacob Tizhe Liberty ${ }^{5}$ \\ ${ }^{1}$ Department of Agricultural and Biosystem Engineering University of Ilorin, Kwara State, Nigeria. \\ 2 Department of Agricultural and Bioresources Engineering Federal University of Technology, Minna, Niger State, Nigeria. \\ ${ }^{3}$ Department of Agricultural and Bioenvironmental Engineering Federal Polytechnic, Bida, Niger State, Nigeria. \\ ${ }^{4}$ Department of Bioresources Engineering, McGill University, Canada.
}

World Journal of Advanced Research and Reviews, 2021, 10(03), 239-245

Publication history: Received on 04 May 2021; revised on 10 June 2021; accepted on 13 June 2021

Article DOI: https://doi.org/10.30574/wjarr.2021.10.3.0229

\begin{abstract}
A response surface methodology (RSM) has been utilized for investigating the effects of the speed of shelling, melon seed moisture content and the number of beaters of a developed mechanized centrifugal melon shelling and cleaning machine. The machine shells the melon and then cleans the shelled seed from the shells and other impurities. The experiment was based on a central composite rotatable design (CCRD). The results of the experiments revealed that the highest shelling efficiency of $88.5 \%$ was obtained from a combination of a speed of $2300 \mathrm{rpm}$, moisture content of $15 \%$ (w.b) and 20 beaters, while the least efficiency of $25.11 \%$ was obtained from an interaction between a speed of 959 rpm, moisture content of $20 \%$ (w.b) and 18 beaters. Numerical optimization carried out with the goal of maximizing the shelling efficiency revealed optimum values of speed of $2200 \mathrm{rpm}$, moisture content of $12 \%$ (w.b) and 19 beaters for shelling efficiency of $88.80 \%$. The result of this study provided standard input parameters capable of yielding high cleaning and recovery efficiency.
\end{abstract}

Keywords: Beaters; Melon; Seed; Shelling; Speed

\section{Introduction}

Melon (Citrullus species), also known as "egusi" in Nigeria, provides numerous socioeconomic and health benefits. Its seed kernels are a good source of edible oil (31-59\%), protein (19-37\%), fibre (3-4\%), and carbohydrate (8-20\%), and contain higher levels of most amino acids than soyabean meal [1]. At present, it is a potential source of oil for biodiesel, which makes it an economically important crop. The seed is high in edible oil, up to $50.2 \%$ on dry weight basis such that its use as a soup condiment [2]. The seed-oil is clear, semi-drying and easily refined-able, suitable for cooking (edible), soap-making, pharmaceuticals and so offers huge prospects for extraction in cottage vegetable oil mills and processing for industrial use. In addition to domestic consumption, Egusi seeds are exported to other countries, generating additional income for farmers [3]. The processing of melon fruit involves the following basic unit operations; drying, washing, fermentation, shelling, coring, and extraction of oil. These operations are mostly done by hand, which makes them difficult, slow, tedious, inefficient, and time-consuming [4]. This has had a significant impact on the production and availability of melon seeds, flour, and oil in markets and stores.Several attempts have been made to address these shortcomings by developing a mechanized system of processing melon seeds and their final products [5]. Among the melon seed processing steps, shelling operation has been reported as one of the labour-intensive operations that can increase the cost of melon kernel production [4]. The locally fabricated melon shelling machines have low shelling

\footnotetext{
* Corresponding author: Gana IM

Department of Agricultural and Bioenvironmental Engineering Federal Polytechnic, Bida, Niger State, Nigeria.

Copyright $(2021$ Author(s) retain the copyright of this article. This article is published under the terms of the Creative Commons Attribution Liscense 4.0.
} 
efficiency and high seed damage [6]. A mechanised centrifugal melon shelling and cleaning machine capable of shelling melon seeds and cleaning the seeds was developed by Olaoye J0 et.al, [7]. The objective of this study is to investigate the effects of shelling speed, melon seed moisture content and number of beaters on the shelling efficiency of the mechanized centrifugal melon shelling and cleaning machine.

\section{Material and methods}

\subsection{Melon seed samples preparation}

Twenty kilograms of melon seeds variety purchased from Minna central Market Niger State Nigeria. The seeds were cleaned of impurities and divided into twenty samples based on the experimental design. Each sample was weighed and soaked in water for ten minutes at a room temperature of $280 \mathrm{C}$ and then subjected to natural air drying in order to obtain the required moisture content of $11.6 \%, 155,20 \%, 25 \%$ and $28.4 \%$ (w.b) based on the design matrix. An instant moisture meter was used to determine their moisture content levels. The samples were processed using the centrifugal melon shelling and cleaning machine based on the design matrix shown in Table 1.

\subsection{Equipment}

A centrifugal melon shelling and cleaning machine (Figure 1) developed by Olaoye J0 et.al., [7] was used in this study. The machine shelled the wet melon and then cleaned it, separating it from the shelled, unshelled and broken ones. The major components of the machine are as follows; hopper, shelling unit, cleaning unit and power transmission unit. The wetted melon with a predetermined moisture content was fed into the machine through the hopper. The hopper neck allows the seeds to pass through to the center of the shelling unit, which is made up of two hard wooden shelling discs. At this point, the electric motor has already been switched on to provide the shelling force needed for the shelling of the melon through the shaft and shelling drum arrangement. The rubber beaters on the shelling discs pounded the fed melon against the metallic encasement, cracking open the shells. The seeds were distributed and thrown by centrifugal force against the shelling vanes where the beaters are attached, which flung the melon against the metallic encasement housing the shelling discs to weaken their shells. The rotating shelling disc assembly generates high air velocity in a whirling pattern at the base of the encasement, so that any seed (shelled, unshelled, or broken) that falls down at the base of the encasement after being beaten is easily blown into the cleaning chamber by the circular motion of the wind. The cleaning chamber serves as a conveying channel which helps to carry the shelled seeds through a piping chamber of varying diameters. In the first large diametric section, the shelled seeds fall freely under gravity and are collected, while the broken and immature grain falls through the second chamber opening. Finally, the chaff was blown out through the final chaff outlet.

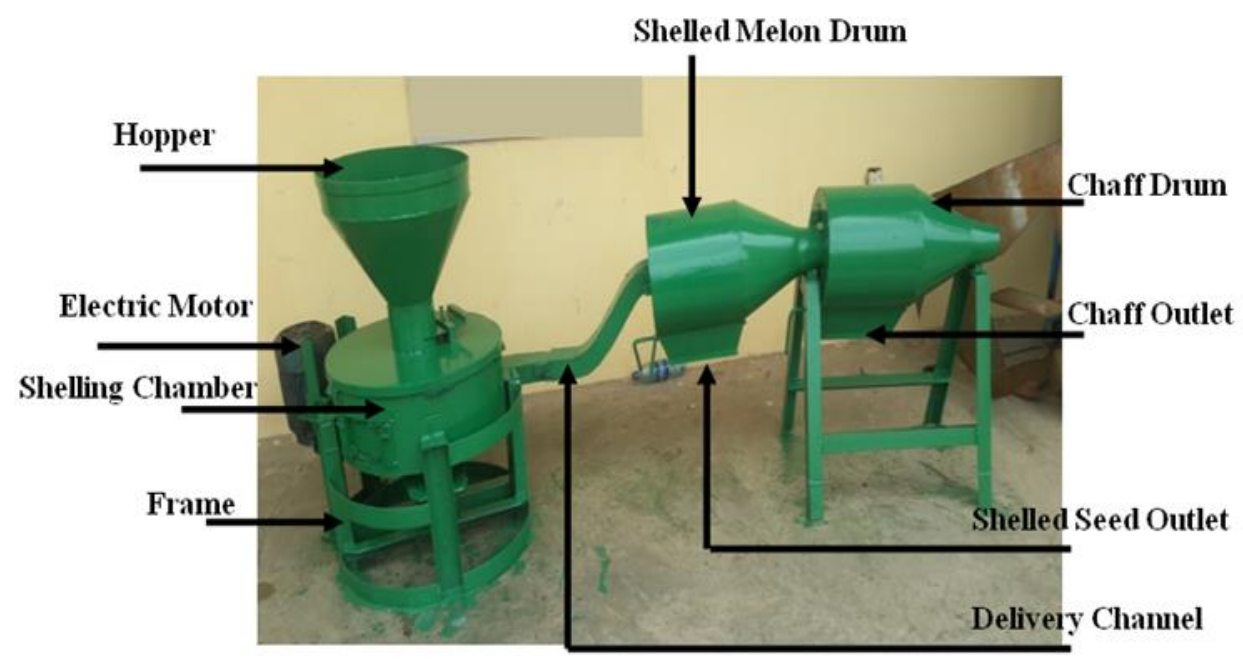

Figure 1 The Developed Melon Shelling and Cleaning Machine (Source:7)

\subsection{Experimental setup and plan}

A Response Surface Methodology was employed in this study using a central composite rotatable design (CCRD). It is made up of three factors that vary by five levels [8]. The CCRD consists of 20 experimental runs $(2 \mathrm{k}+2 \mathrm{k}+\mathrm{m}$, where $\mathrm{k}$ 
is the number of factors and $\mathrm{m}$ is the number of replicated centre points), comprised of eight factorial points (2k), six axial points $(2 \mathrm{k})$, and six replicated centre points $(\mathrm{m}=6)$. The three factors are speed, melon seed moisture content and the number of beaters. The beater hits the melon seeds and thereby separates the seed from the shell. It was varied at configurations of 15,16,18, 20 and 21 numbers. The seed moisture content level varied from 11.6\%, 155, 20\%, 25\% and $28.4 \%$ (w.b). The speed of the machine varied from $960 \mathrm{rpm}, 1300 \mathrm{rpm}, 1800 \mathrm{rpm}, 2300 \mathrm{rpm}$ and $2640 \mathrm{rpm}$. The experiment was conducted based on the design matrix shown in Table 1.

\subsection{Experimental procedure}

The component parts of the machine were assembled as reported by Olaoye J0 et.al., [7]. The machine's electric motor was switched on; the wetted melon was fed into the machine through the hopper. The seeds flowed down to the shelling chamber where they were distributed and thrown by centrifugal force against the shelling vanes on which the beaters were attached. The flinging of the seed against the metallic encasement housing the shelling discs weakens their shells, in order to facilitate the shelling operation. The rotating shelling disc assembly generates high air velocity in a whirling pattern at the base of the encasement, so that any seed (shelled, unshelled, or broken) that falls down at the base of the encasement after being beaten is easily blown into the cleaning chamber by the circular motion of the wind. The cleaning chamber serves as a conveying channel which helps to carry the shelled seeds through a piping chamber of varying diameters. In the first large diametric section, the shelled seeds fall freely under gravity and are collected, while the broken and immature grain falls through the second chamber opening. Finally, the chaff was blown out through the final chaff outlet.

\subsection{Determination of Shelling Efficiency}

The shelling efficiency was determined as reported by Olaoye JO et.al., [7], and is given as

$$
S h_{e f f}=\frac{M_{S S}}{M_{E S}} \times 100
$$

Where, $S h_{e f f}$ is the shelling efficiency (\%), $M_{S S}$ is the mass of shelled seed (g), $M_{E S}$ is the mass of the expected shelled seed $(\mathrm{g})$

\subsection{Statistical Analysis}

A Minitap software package was used for the regression and graphical analysis. A quadratic polynomial equation was developed to predict the shelling efficiency as a function of independent variables and their interaction.

\section{Results and discussion}

The effects of independent variables, speed, moisture content and number of beaters, on shelling efficiency are presented in Table 1 . The shelling efficiency ranged from $25.11 \%$ to $88.5 \%$. The highest value of $88.5 \%$ was obtained from a combination of speed of $2300 \mathrm{rpm}$, moisture content of 15\% (w.b) and 20 beaters, while the least efficiency of $25.11 \%$ was obtained from an interaction between speed of 959 rpm, moisture content of $20 \%$ (w.b) and 18 beaters. The result of the statistical analysis of variance (ANOVA) of the experiment showed that the model terms were significant. The significant model terms were identified at the 95\% significance level. The Quadratic regression model equation developed to predict the shelling efficiency with respect to independent variables is shown in equation 2 . The model F, with a value of 453.8, implies that the model is significant. The value of Probability $>\mathrm{F}$ of less than 0.0500 indicated that the model terms were significant. In this case, $A, B, C, A B, A C, A 2$, and $C 2$ were significant model terms. The "Lack of Fit F-value" of 3.23 indicates that the lack of fit is insignificant in comparison to a pure error. Non-significant lack of fit is good [8]. The coefficient of determination $\mathrm{R}$ value of 0.9969 indicated that the model was able to predict $99.69 \%$ of the variance and only $0.31 \%$ of the total variance was not explained by the model. The coefficient of correlation R-squared value of 0.9939 was very close to the recommended value of 1 as recommended by Xin L et.al.,[9]. The Predicted R - Squared of 96.94\% was in reasonable agreement with the Adjusted R - Squared of 0.994, which indicated that the experimental data fitted better [10]. This indicates that the model can be used to navigate the design space. The fitted shelling efficiency model equation is given as:

$$
S h_{e f f}=-453.8+0.1321 A+6.89 B+31.99 C-0.001711 A B-0.000024 A^{2}-0.791 C^{2}
$$

It is obvious that the entire variables in the model have positive co-efficient implying a direct proportionality. That is an independent increase in any of the variables the shelling efficiency increased. 
Table 1 Matrix transformation of five level- three factors central composite rotatable design of the experiment

\begin{tabular}{|c|c|c|c|c|c|}
\hline Std Order & Run Order & Speed & Moisture content & No. of Beaters & Shelling Efficiency \\
\hline 4 & 1 & 2300 & 25 & 16 & 55.6 \\
\hline 10 & 2 & 2641 & 20 & 18 & 75.53 \\
\hline 16 & 3 & 1800 & 20 & 18 & 67.34 \\
\hline 14 & 4 & 1800 & 20 & 21 & 70.89 \\
\hline 13 & 5 & 1800 & 20 & 15 & 46.5 \\
\hline 15 & 6 & 1800 & 20 & 18 & 67.23 \\
\hline 11 & 7 & 1800 & 11.60 & 18 & 73.6 \\
\hline 8 & 8 & 2300 & 25 & 20 & 70.65 \\
\hline 20 & 9 & 1800 & 20 & 18 & 68.33 \\
\hline 17 & 10 & 1800 & 20 & 18 & 68 \\
\hline 9 & 11 & 959 & 20 & 18 & 25.11 \\
\hline 5 & 12 & 1300 & 15 & 20 & 48.44 \\
\hline 3 & 13 & 1300 & 25 & 16 & 37.13 \\
\hline 1 & 14 & 1300 & 15 & 16 & 34.6 \\
\hline 12 & 15 & 1800 & 28.41 & 18 & 51.5 \\
\hline 18 & 16 & 1800 & 20 & 18 & 67 \\
\hline 2 & 17 & 2300 & 15 & 16 & 74.05 \\
\hline 7 & 18 & 1300 & 25 & 20 & 42.63 \\
\hline 19 & 19 & 1800 & 20 & 18 & 65.4 \\
\hline 6 & 20 & 2300 & 15 & 20 & 88.5 \\
\hline
\end{tabular}

Table 2 Regression analysis of response of shelling efficiency

\begin{tabular}{|c|c|c|c|c|c|c|}
\hline Source & $\begin{array}{l}\text { Coefficient } \\
\text { of estimate }\end{array}$ & $\begin{array}{c}\text { SE } \\
\text { Coefficient }\end{array}$ & F - value & $\begin{array}{l}\text { P-value } \\
\text { Prob >F }\end{array}$ & \multicolumn{2}{|c|}{ R-Squared } \\
\hline Model & -453.8 & 0.720 & 180.63 & $<0.0001$ & 0.9939 & Significant \\
\hline A-Speed (rpm) & 0.1312 & 0.477 & 1044.22 & $<0.0001$ & & \\
\hline $\begin{array}{l}\text { B-Moisture } \\
\text { content }(\%)\end{array}$ & 6.89 & 0.477 & 137.34 & $<0.0001$ & & \\
\hline C-No of beater & 31.99 & 0.477 & 188.94 & $<0.0001$ & & \\
\hline $\mathrm{AB}$ & -0.001711 & 0.465 & 47.02 & $<0.0001$ & & \\
\hline $\mathrm{AC}$ & 0.001120 & 0.465 & 3.22 & 0.103 & & \\
\hline $\mathrm{BC}$ & -0.1130 & 0.465 & 3.28 & 0.100 & & \\
\hline$A^{\wedge} 2$ & -0.000024 & 0.624 & 166.27 & $<0.0001$ & & \\
\hline $\mathrm{B}^{\wedge} 2$ & -0.0724 & 0.624 & 15.17 & 0.003 & & \\
\hline $\mathrm{C}^{\wedge} 2$ & -0.791 & 0.624 & 46.31 & $<0.0001$ & & \\
\hline Lack of Fit & & & 3.23 & 0.112 & & $\begin{array}{l}\text { Not } \\
\text { Significant }\end{array}$ \\
\hline
\end{tabular}




\subsection{Response surface and contour plot for shelling efficiency}

The response surface and contour plot for shelling efficiency are presented in Figures 2 and 3. Figures 2 and 3 show that increasing the shelling speed from $1000 \mathrm{rpm}$ to $1200 \mathrm{rpm}$ increased shelling efficiency from $15 \%$ to $65 \%$, and then remained constant with a further increase to $2800 \mathrm{rpm}$. This could be due to the beating action of the beaters on the seeds and the high degree of centrifugal impact of the melon against the metallic encasement with an increase in the speed of shelling. This trend followed a similar pattern to a study conducted on pistachio nuts by Khodabakhshian $\mathrm{R}$ et.al.,[11] and on the shelling of shea nuts by Shehu et al. (2018). In addition, with an increase in beater numbers from 14 to 20 , shelling efficiency increased from $65 \%$ to $84 \%$. This could be due to an increase in beating and contact action among the beaters as their numbers increase. This agreed with the results of an earlier study by Wangette IS et.al, [12], where increases in speed and beaters of groundnut shelling machines resulted in an increase in collision and rubbing actions that generate the forces that causes the shelling of the groundnut pods.

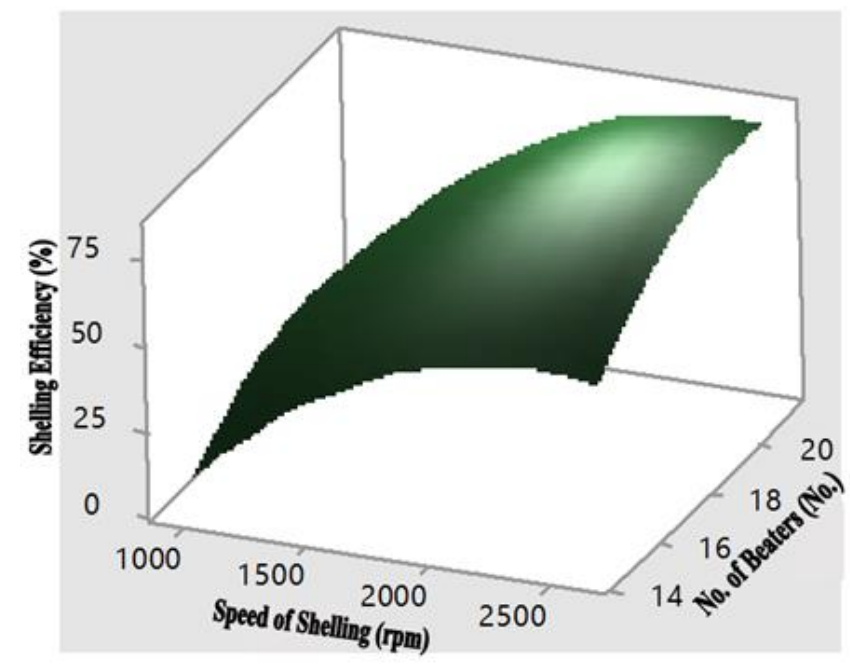

Figure 2 Response surface for effects of speed of shelling and number of beaters on shelling efficiency

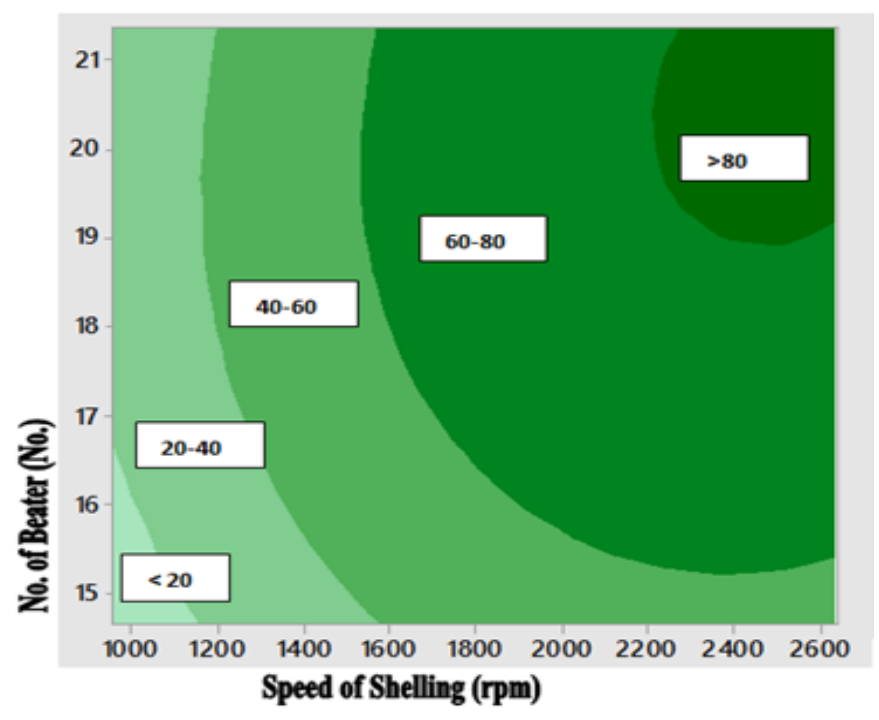

Figure 3 Contour plot effects of speed of shelling and number of beaters on shelling efficiency

From Figures 4 and 5, the shelling efficiency was observed to increase from $22 \%$ to $80 \%$ with an increase in the speed of shelling from $1000 \mathrm{rpm}$ to $1200 \mathrm{rpm}$ and then remained constant with a further increase in speed to $2500 \mathrm{rpm}$. This could be due to the beating action of the beaters on the seeds and the high degree of centrifugal impact of the melon against the metallic encasement with an increase in the speed of shelling. This trend followed a similar pattern to studies conducted on pistachio nuts by Khodabakhshian R et.al.,[11] and on the shelling of Shea nuts by Shehu AA et.al,[13]. Also, shelling efficiency increased from $58 \%$ to $80 \%$ with a decrease in moisture content from $25 \%$ to $15 \%$, and then remained constant with a further decrease in the melon seed moisture content to $5 \%$. This is in line with an earlier 
study by El Shal MS et.al, [14] on the effects of some operational factors on the hammer mill, where the fineness of grain was increased with a decrease in the grain moisture content

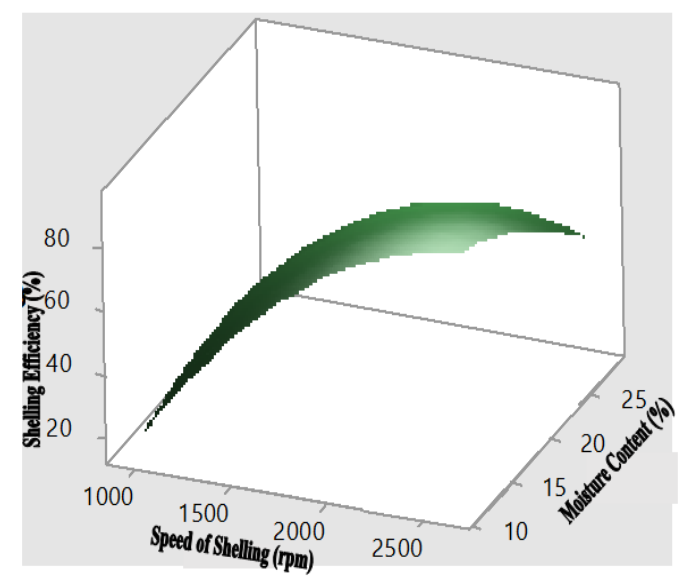

Figure 4 Response surface for effects of speed of shelling and moisture content on shelling efficiency

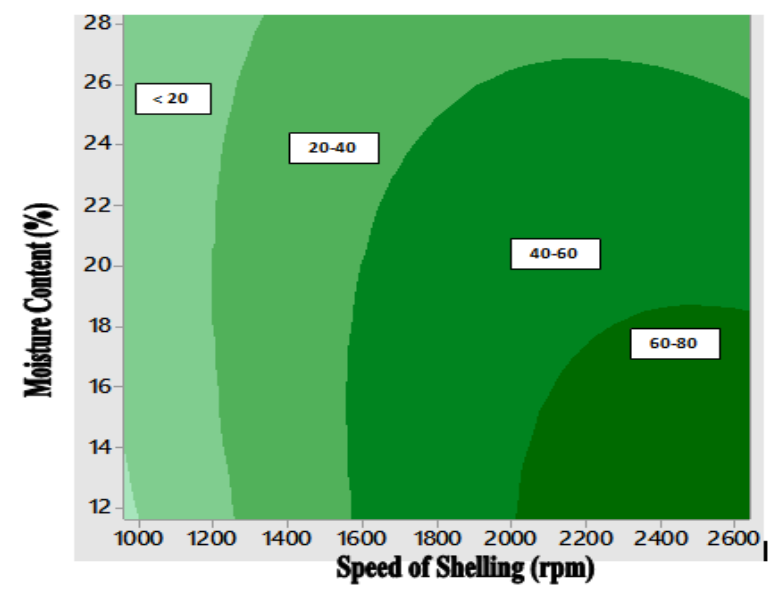

Figure 5 Contour plot effects of speed of shelling and moisture content on shelling efficiency

\subsection{Optimization of the parameters}

The ramp for the optimization is shown in Figure 6. Optimizing the parameters with the goal of maximizing the shelling efficiency gave the optimum values of speed of $2200 \mathrm{rpm}$, moisture content of $12 \%$ (w.b) and 19 beaters for a shelling efficiency of $88.80 \%$ as shown in Figure 6

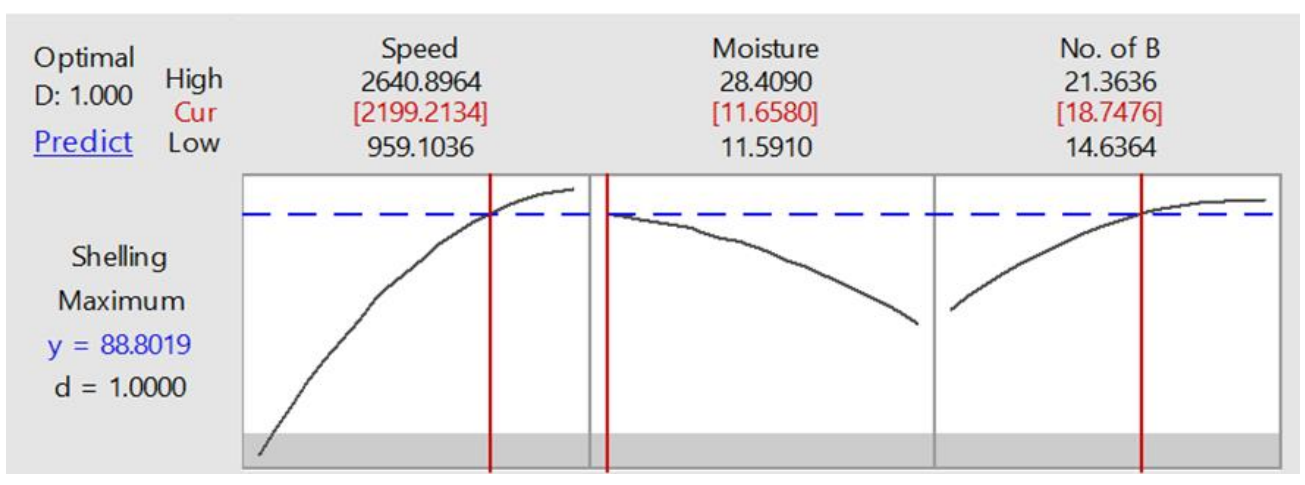

Figure 6 Ramp for optimization of shelling efficiency 


\section{Conclusion}

The effects of parameters of a centrifugal melon shelling and cleaning machine were studied and the major conclusions were as follows: the shelling efficiency increased with an increase in the speed of blending from $1000 \mathrm{rpm}$ to $1200 \mathrm{rpm}$ and an increase in the number of beaters from 14 to 20 . But a decrease means an increase in the seed moisture content from $15 \%$ to $25 \%$ (w.b). Optimum values of speed of $2200 \mathrm{rpm}$, moisture content of $12 \%$ (w.b) and 19 beaters for shelling efficiency of $88.80 \%$ with the goal of maximizing the shelling efficiency.

\section{Compliance with ethical standards}

\section{Acknowledgments}

The authors gratefully acknowledge the Department of Agricultural and Biosystem Engineering University of Ilorin, Kwara State, Nigeria and the Department of Agricultural and Bioresources Engineering Federal University of Technology, Minna, Niger State, Nigeria for supporting this work.

\section{Disclosure of conflict of interest}

The authors declare that there is no conflict of interests regarding the publication of this paper

\section{References}

[1] Ogbonna PE. Yield Responses of “Egusi” Melon (Colocynthis citrullus L.) to rates of NPK 15:15:15 Fertilizer: Am.Eurasian J. Sustain. Agric. 2009; 3(4): 764-770.

[2] Adewusi HG, Ladipo DO, Sarumi MB, Adebisi AA, Vodouhe R. Egusi production, utilization and diversity in Nigeria. In: Akoroda, M.O. (compiler). Agronomy in Nigeria: a book in support of Agronomy Re-Union Day. Department of Agronomy, University of Ibadan. 04 October 2000; 94-100.

[3] Van der Vossen HAM, Denton OA, El-Tahir IM, Citrullus lanatus (Thumb); Matsum and Nakai. In: Grubben, GJH. and Denton OA. (ed). Plant Resources of Tropical Africa 2. Vegetables. PROTA Foundation, Wageningen. The Netherlands. 2004.

[4] Adekunle A, Ohijeagbon I, Olusegun H. Development and performance evaluation of manually and motorized operated melon shelling machine using impact technique, J. Eng. Sci. Technol. 2009; Rev. 2(1): 12-17.

[5] Oladimeji ST, Oyerinde AS, Ogunlade CA. Development and evaluation of a melon shelling machine, Adeleke Uni. J. Eng. Technol. 2009; 2: 149-155.

[6] Shittu, SK, Ndrika VIO. Development and performance tests of a melon (egusi)seed shelling machine. Agric Eng Int: CIGR Journal. 2012; 14(1): 157-164.

[7] Olaoye JO, Aturu OB. Design and fabrication of a mechanised centrifugal melon shelling and cleaning machine. International Journal of Agricultural Technology. 2018; 14(6): 881-896.

[8] Gana IM, Agidi G, Idah PA, Anuonye JC. Development and testing of an automated grain drinks processing machine. Journal of Food and Bioproducts Processing. 2017; 104: 19-31.

[9] Xin L, Saka S. Optimization of Japanese beech hydrolysis treated with batch hot compressed water by response surface methodology. International Journal of Agricultural Biological and Engineering. 2008; 1(2): $239-245$.

[10] Salam KK, Arinkoola AO, Oke EO, Adeleye JO. Optimization of operating parameters using response surface methodology for paraffinwax deposition in pipeline. Petroleum and Coal. 2014; 56 (1): 19-28.

[11] Khodabakhshian R, Bayati MR, Shakeri M. Performance evaluation of a centrifugal peeling system for pistachio nuts. International Journal of Food Engineering. 2011; 7(4): 1-10.

[12] Wangette IS, Nyaanga DM, Njue MR. Influence of groundnut and machine characteristics on motorised sheller performance. J Agric For. 2015; 3(5): 178-191.

[13] Shehu AA, Gana IM, Balami AA. Development and Testing of Indigenous Shea Butter Processing Plant in Nigeria. Journal of Food Chemistry \& Nanotechnology. J Food Chem Nanotechnol. 2018; 4(2): 38-50.

[14] El Shal MS, Tawfik MA, El Shal AM, Metwally KA. Study the effect of some operational factors on hammer mill. Misr J Ag Eng. 2010; 27(1): 54-74. 